\title{
Cerebral Responses to Acute Maternal Alcohol Intoxication in Immature Fetal Sheep ${ }^{1}$
}

\author{
CHRISTINE A. GLEASON AND KAREN J. HOTCHKISS \\ Eudowood Neonatal Pulmonary Division, Department of Pediatrics, Anesthesiology/Critical Care Medicine and \\ Gynecology and Obstetrics, The Johns Hopkins University, Baltimore, Maryland 21205 and Cardiovascular \\ Research Institute, University of California, San Francisco, San Francisco. California 94143
}

\begin{abstract}
Previous studies in mature fetal sheep have shown that alcohol depresses cerebral blood flow (CBF), cerebral $\mathrm{O}_{2}$ consumption $\left(\mathrm{CMRO}_{2}\right)$, and cerebral glucose consumption (CMRglu). This effect earlier in gestation might contribute to the pathogenesis of fetal alcohol syndrome. Physiologic studies of immature fetal sheep have demonstrated lower $\mathrm{CBF}, \mathrm{CMRO}_{2}$, and $\mathrm{CMRglu}$ as well as a blunted vasodilatory response to hypoxia compared with mature fetal sheep. The purpose of this study was to determine whether immature fetal responses to alcohol are blunted compared with near-term fetal responses. We studied seven immature fetal sheep in utero at $92 \pm 1 \mathrm{~d}$ gestation (term $=147 \mathrm{~d}) 2 \mathrm{~d}$ after placement of vascular catheters. Pure ethanol $(1 \mathrm{~g} / \mathrm{kg})$ was infused i.v. to the mother over $1 \mathrm{~h}$. We measured $\mathrm{CBF}$ and myocardial blood flow by radioactive microspheres and calculated $\mathrm{CMRO}_{2}$ and CMRglu using arterial and sagittal sinus $\mathrm{O}_{2}$ and glucose concentrations. At a fetal ethanol concentration of $33+8 \mathrm{mmol} / \mathrm{L}(150 \pm 37 \mathrm{mg} / \mathrm{dL})$, there were no significant changes in $\mathrm{CBF}, \mathrm{CMRO}_{2}$, or CMRglu. There was mild hypoglycemia (glucose concentration $=1.05 \pm 0.2$ versus $1.33 \pm 0.2 \mathrm{mM}$ baseline) and lactic acidemia (lactate concentration $=1.29 \pm 0.3$ versus $1.07 \pm 0.2 \mathrm{mM}$ baseline) . Cardiovascular variables were unchanged as was myocardial blood flow. The immature fetal sheep brain shows no significant cerebrovascular and metabolic response to acute alcohol intoxication compared with mature fetal sheep. Mild hypoglycemia and lactic acidemia did develop. The reason for the developmental differences in response to alcohol and their relationship to fetal alcohol syndrome remain to be elucidated. (Pediatr Res 31: 645-648, 1992)
\end{abstract}

\section{Abbreviations}

CBF, cerebral blood flow

$\mathrm{CMRO}_{2}$, cerebral $\mathrm{O}_{2}$ consumption

CMRglu, cerebral glucose consumption

Alcohol is the foremost drug of abuse in the United States, and maternal alcohol abuse, resulting in the fetal alcohol syndrome, is one of the leading causes of mental retardation $(1,2)$. Neurologic features of the fetal alcohol syndrome include microcephaly, hydrocephalus, abnormalities of neuronal migration ("heterotopias"), cerebellar hypoplasia, low intelligence quotient,

Received August 27, 1991; accepted February 4, 1992

Correspondence: Christine A Gleason, MD Division of Neonatology, The Johns Hopkins Hospital, CMSC 210, 600 N. Wolfe Street Baltimore, MD 21205. Supported in part by Committee on Research. Academic Senate, University of California, San Francisco.

Presented in part at the annual meeting of the Society for Pediatric Research, April 30, 1991. and behavioral problems (3). Several of these neurologic abnormalities have been produced in animals exposed to alcohol in utero (4). However, the mechanism(s) by which alcohol produces brain damage and the vulnerable developmental period (if any) during which damage occurs are unknown. The depressant effects of alcohol on $\mathrm{CBF}$ and $\mathrm{CMRO}_{2}$ have been previously reported in several adult animal models as well as in mature fetal sheep. Richardson et al. (5) studied the physiologic responses of term fetal sheep to acute maternal alcohol intoxication and noted a significant decrease in both $\mathrm{CBF}$ and $\mathrm{CMRO}_{2}$. In addition, they noted significant fetal hypoglycemia and a decrease in CMRglu. The fetal sheep brain is very mature near term, both structurally and functionally. Studies of immature fetal sheep have shown significantly lower $\mathrm{CBF}, \mathrm{CMRO}_{2}$, and $\mathrm{CMRglu}$ compared with mature fetal sheep (6). Furthermore, the cerebral vasodilatory response to hypoxemia is "blunted," reflecting either immature regulatory mechanisms or an inability of cerebral vessels to respond to the usual stimuli (7). We theorized that cerebral responses to acute maternal alcohol intoxication may be similarly blunted or absent in immature fetal sheep, and we therefore compared the physiologic responses to acute alcohol intoxication in immature fetal sheep with responses previously reported near term.

\section{MATERIALS AND METHODS}

Subjects. Before initiating these studies, all surgical and experimental procedures were approved by the Animal Care and Use Committee at the University of California, San Francisco. Seven mixed-breed fetal sheep were obtained from time-dated pregnancies.

Surgical preparation. One d before surgery, food was withheld from the ewe, although she was allowed free access to water. After local anesthesia (2\% lidocaine hydrochloride), spinal anesthesia was achieved by injecting $4 \mathrm{~mL}$ of $1 \%$ tetracaine hydrochloride (Pontocaine $\mathrm{HCl}$; Breon Laboratories, New York, NY). Ketamine hydrochloride (50 to $100 \mathrm{mg}$, Vetalar; Parke-Davis, Morris Plains, NJ) was administered i.v. every 15-30 min during surgery. Local anesthesia $(0.25 \%$ lidocaine hydrochloride) was used for all fetal incisions. In the ewe, polyvinyl catheters were placed into the descending aorta and inferior vena cava via pedal vessels. An i.v. infusion of $10 \%$ dextrose in $0.9 \% \mathrm{NaCl}$ was begun. Approximately $1 \mathrm{~L}$ was infused over $2 \mathrm{~h}$ during surgery. In the fetus, polyvinyl catheters were placed into the axillary artery, femoral artery, inferior vena cava (via a pedal vein), and sagittal sinus by previously described methods (6). A catheter was also placed into the amniotic cavity. All vascular catheters were filled with heparin sodium solution $(500 \mathrm{U} / \mathrm{mL})$ and sealed. Uterine and abdominal incisions were closed, and all catheters were exteriorized through the ewe's flank. Antibiotics (400 mg kanamycin, $1000000 \mathrm{U}$ penicillin $\mathrm{G}$ ) were given into the amniotic cavity and maternal vein on the day of surgery and each day thereafter. 
The ewe was fed a standard diet of hay and alfalfa pellets and allowed $48 \mathrm{~h}$ to recover before physiologic studies of the fetus in utero.

Physiologic measurements. Blood flow was measured by use of the radiolabeled microsphere technique (8). Approximately 800000 microspheres (selected from ${ }^{57} \mathrm{Co},{ }^{51} \mathrm{Cr},{ }^{153} \mathrm{Gd},{ }^{114} \mathrm{In}$, ${ }^{54} \mathrm{Mn},{ }^{95} \mathrm{Nb},{ }^{113} \mathrm{Sn},{ }^{85} \mathrm{Sr}$, or ${ }^{65} \mathrm{Zn}$ ) were injected over $0.5 \mathrm{~min}$ into the inferior vena cava, followed by $1.5 \mathrm{~mL}$ of donor fetal blood. A reference blood sample was withdrawn from the axillary artery at a rate of $2.0 \mathrm{~mL} / \mathrm{min}$, beginning $10-20 \mathrm{~s}$ before the microsphere injection and continuing for $1.0 \mathrm{~min}$ after the injection was completed. After completion of the study, the ewe was killed with an i.v. injection of sodium pentobarbital $(6-10 \mathrm{~g})$ followed by bilateral thoracotomy. The fetus was immediately removed from the uterus and weighed, followed by immediate removal and weighing of the brain and heart. The brain was divided at the cephalic border of the pons. All tissue rostral to that point was pooled and counted to determine CBF. The cerebellum was removed at the peduncles and counted separately, as was the pons-medulla. The tissue samples were weighed and then placed in formalin. They were later carbonized in an oven at $177^{\circ} \mathrm{C}$, ground into a powder, placed in plastic vials at a uniform height of $3 \mathrm{~cm}$, and counted in a 1000-channel multichannel pulseheight analyzer (Norland Corp., Fort Atkinson, WI). The activity of each isotope in each organ was determined by the least squares method. All reference blood and tissue samples contained $>400$ microspheres.

Blood samples for $\mathrm{pH}$, respiratory blood gases, $\mathrm{Hb}$ concentration, oxygen saturation, and glucose, lactate, and ethanol concentration were drawn into heparinized tuberculin syringes and capped immediately. Respiratory blood gases and $\mathrm{pH}$ were measured at $39^{\circ} \mathrm{C}$ with the Corning 158 blood gas analyzer (Corning Medical, MA). Oxygen saturation and $\mathrm{Hb}$ concentration were measured with the OSM-2 Hemoximeter (Radiometer, Copenhagen, Denmark). Blood glucose and lactate concentrations were measured using the YSI model 2300 glucose-lactate analyzer (Yellow Springs Instrument Co., Inc., Yellow Springs, $\mathrm{OH}$ ). Blood ethanol concentration was measured enzymatically via alcohol dehydrogenase oxidation (Sigma Diagnostics, St. Louis, $\mathrm{MO}$ ). Arterial blood pressure (referenced to amniotic fluid pressure) and heart rate were continuously monitored using Statham P23D6 strain-gauge transducers, Beckman R612, (Beckman Instruments, Fullerton, CA) or Gould 2800 S (Gould Inc., Cleveland, $\mathrm{OH})$ polygraphs and a cardiotachometer.

Experimental protocol. On the day of study, $48 \mathrm{~h}$ after surgery, the ewe was brought to the laboratory and placed in a specially designed study cart allowing access to food and water. The ewe was allowed 1-2 $\mathrm{h}$ to become accustomed to her surroundings before the study began. Three measurements were obtained during the study. For each measurement, blood samples were simultaneously drawn from the maternal artery and the fetal axillary artery and sagittal sinus catheters $(0.3 \mathrm{~mL}$ from each vessel) and analyzed for $\mathrm{pH}$, blood gases, $\mathrm{Hb}$ concentration, and lactate, glucose, and ethanol concentrations. Immediately after blood samples were obtained, radiolabeled microspheres were injected into the inferior vena cava catheter while a reference sample was obtained from the axillary artery. All withdrawn blood was replaced immediately ( $\mathrm{mL}$ for $\mathrm{mL}$ ) with donor fetal sheep blood. Heart rate and blood pressure, monitored continuously, were averaged over $5 \mathrm{~min}$ for each measurement period. There were no changes in heart rate or blood pressure associated with microsphere injections or blood samplings.

Immediately after baseline measurements were obtained, an infusion of pure ethanol, $1 \mathrm{~g} / \mathrm{kg}$, diluted $1: 2$ in $0.9 \%$ saline, was begun i.v. to the ewe and continued over $1 \mathrm{~h}$. The second measurement was obtained at the end of the $1-\mathrm{h}$ infusion and the third measurement $2 \mathrm{~h}$ thereafter; henceforth, the third measurement will be called the 3-h measurement.

The $1-\mathrm{g} / \mathrm{kg}$ alcohol dose is identical to the dose used by Richardson et al. (5) in their studies of term fetal sheep and is equivalent to approximately $7.5 \mathrm{oz}$. of 80 -proof alcohol or six alcoholic "drinks."

Data analysis and calculations. Organ blood flow was calculated as organ blood flow $=(\mathrm{cpm}$ organ $/ \mathrm{cpm}$ ref $) \times$ reference sample withdrawal rate, in which cpm represents radioactive counts per min and ref represents the reference withdrawal sample.

$\mathrm{CMRO}_{2}$ was calculated as $\mathrm{CMRO}_{2}=\left[\mathrm{CAO}_{2}-\mathrm{CvO}_{2}\right] \times \mathrm{CBF}$, in which $\mathrm{CaO}_{2}$ and $\mathrm{CvO}_{2}$ represent arterial and venous oxygen contents, respectively, and CBF represents blood flow to all cerebral tissue rostral to the pons. CMRglu was calculated similarly. Cerebral oxygen transport (OT) was calculated as OT = $\mathrm{CaO}_{2} \times \mathrm{CBF}$. Cerebral fractional oxygen extraction (E) was calculated as $\mathrm{E}=\mathrm{CMRO}_{2} / \mathrm{OT}$.

Measurements were calculated as mean \pm SD for all the study fetuses. Measurements during alcohol intoxication were compared with baseline measurements by analysis of variance. If the $F$ test was significant, specific differences were sought with the Newman-Keuls test. Significance was considered at $p \leq 0.05$.

\section{RESULTS}

We studied seven fetal sheep at a mean gestational age of 92 $\pm 1 \mathrm{~d}$. The fetuses ranged in age from 91 to $95 \mathrm{~d}$ of gestation at the time of study and weighed $730 \pm 50 \mathrm{~g}$. Because sheep reach full term at approximately $147 \mathrm{~d}$ of gestation, fetuses were approximately two-thirds gestation. Four of the fetuses were one of twins. Four were males. In one of the seven fetuses, baseline blood flow measurements could not be analyzed, and in another blood could not be withdrawn from the sagittal sinus catheter.

Blood ethanol concentrations after the 1 -h ethanol infusion were $32 \pm 6 \mathrm{mmol} / \mathrm{L}$ (maternal) and $3.3 \pm 8 \mathrm{mmol} / \mathrm{L}$ (fetal) Two $\mathrm{h}$ after the infusion was completed, ethanol concentrations had declined to $23 \pm 9 \mathrm{mmol} / \mathrm{L}$ (maternal) and $25 \pm 10 \mathrm{mmol} /$ $\mathrm{L}$ (fetal). There were no significant differences between maternal and fetal concentrations. It is interesting to note that our immature fetal ethanol levels were similar to levels obtained by Richardson et al. (5) in mature fetuses, suggesting that the pharmacokinetics of placental ethanol transfer are unchanged over the last half of pregnancy. For reference, legal intoxication for driving while intoxicated in most of the United States is charged at a blood ethanol concentration of $22 \mathrm{mmol} / \mathrm{L}(100$ $\mathrm{mg} / \mathrm{dL})$, significant narcosis occurs at $43 \mathrm{mmol} / \mathrm{L}(200 \mathrm{mg} / \mathrm{dL})$, and stupor and coma occurs at $65 \mathrm{mmol} / \mathrm{L}(300 \mathrm{mg} / \mathrm{dL})(1)$. During the 1-h infusion, the sheep became drowsy and unbalanced; they often sat down. They appeared fully recovered by the 3-h measurement.

Cardiovascular and systemic physiologic variables are shown in Table 1. There were no significant changes during alcohol intoxication other than a physiologically insignificant decrease in $\mathrm{pH}$ and mean arterial blood pressure $1 \mathrm{~h}$ after the infusion was completed.

The effect of acute alcohol intoxication on regional brain blood flow and myocardial blood flow is shown in Table 2. There were

Table 1. Fetal cardiovascular and physiologic variables before and during acute maternal alcohol intoxication $(n=7$ immature fetal sheep)

\begin{tabular}{lccc}
\hline & Baseline & $\begin{array}{c}\text { Ethanol } \\
\mathrm{l} \mathrm{h}\end{array}$ & $\begin{array}{c}\text { Postethanol } \\
3 \mathrm{~h}\end{array}$ \\
\hline Arterial pH & $7.35 \pm 0.03$ & $7.33 \pm 0.04^{*}$ & $7.35 \pm 0.02$ \\
$\mathrm{PCO}_{2}(\mathrm{kPa})$ & $6.6 \pm 0.4$ & $6.8 \pm 0.6$ & $6.8 \pm 0.4$ \\
$\mathrm{PO}_{2}(\mathrm{kPa})$ & $3.6 \pm 0.2$ & $3.9 \pm 0.2$ & $3.6 \pm 0.4$ \\
$\mathrm{Hb}(\mathrm{g} / \mathrm{L})$ & $80 \pm 9$ & $80 \pm 12$ & $81 \pm 11$ \\
$\mathrm{O}_{2}$ saturation $(\%)$ & $65.9 \pm 5.7$ & $70.9 \pm 2.4$ & $67.3 \pm 6.9$ \\
$\mathrm{MAP}(\mathrm{mm} \mathrm{Hg}) \dagger$ & $36 \pm 4$ & $34 \pm 3^{*}$ & $36 \pm 3$ \\
Heart rate $(\mathrm{bpm})$ & $221 \pm 19$ & $208 \pm 7$ & $226 \pm 18$ \\
\hline
\end{tabular}

${ }^{*} p \leq 0.05$, compared with baseline.

$\dagger$ MAP, mean arterial blood pressure. 
Table 2. Regional brain blood flow and myocardial blood flow $(\mathrm{mL} / 100 \mathrm{~g} / \mathrm{min})$ before and during acute maternal alcohol intoxication ( $n=6$ immature fetal sheep)

\begin{tabular}{lcrc}
\hline & & $\begin{array}{c}\text { Ethanol } \\
1 \mathrm{~h}\end{array}$ & \multicolumn{1}{c}{$\begin{array}{c}\text { Postethanol } \\
3 \mathrm{~h} \mathrm{~h}\end{array}$} \\
\hline $\begin{array}{l}\text { Cerebral hemispheres } \\
\quad \text { and midbrain }\end{array}$ & $60 \pm 14$ & $52 \pm 13$ & $56 \pm 18$ \\
Cerebellum & $103 \pm 29$ & $84 \pm 32$ & $93 \pm 51$ \\
Brainstem & $122 \pm 21$ & $96 \pm 26$ & $105 \pm 38$ \\
Myocardium & $171 \pm 20$ & $148 \pm 26$ & $164 \pm 34$ \\
\hline
\end{tabular}

Table 3. Cerebral oxygen metabolism before and during acute maternal alcohol intoxication in immature fetal sheep

\begin{tabular}{lccc}
\hline & & Ethanol & $\begin{array}{c}\text { Postethanol } \\
3 \mathrm{~h}\end{array}$ \\
\hline $\mathrm{CaO}_{2}(n=7)^{*}$ & $3.2 \pm 0.5$ & $3.4 \pm 0.5$ & $3.3 \pm 0.7$ \\
$\mathrm{CMRO}_{2}(n=5) \dagger$ & $60 \pm 11$ & $50 \pm 14$ & $71 \pm 16$ \\
$\mathrm{OT}(n=6) \ddagger$ & $196 \pm 38$ & $183 \pm 38$ & $196 \pm 71$ \\
$\mathrm{O}_{2}$ extraction & $0.32 \pm 0.04$ & $0.30 \pm 0.09$ & $0.35 \pm 0.07$ \\
$(n=6)$ & & & \\
\hline
\end{tabular}

${ }^{*} \mathrm{CaO}_{2}$, arterial $\mathrm{O}_{2}$ content $(\mathrm{mmol} / \mathrm{L})$.

† $\mathrm{CMRO}_{2}$, cerebral $\mathrm{O}_{2}$ consumption $(\mu \mathrm{mol} / 100 \mathrm{~g} / \mathrm{min})$.

¥OT, cerebral $\mathrm{O}_{2}$ transport $(\mu \mathrm{mol} / 100 \mathrm{~g} / \mathrm{min})$.

Table 4. Cerebral glucose and lactate metabolism before and during acute maternal alcohol intoxication

\begin{tabular}{lccc}
\hline & & $\begin{array}{c}\text { Ethanol } \\
1 \mathrm{~h}\end{array}$ & $\begin{array}{c}\text { Postethanol } \\
3 \mathrm{~h}\end{array}$ \\
\hline $\begin{array}{l}\text { Maternal CaGlu } \\
(n=7)^{*}\end{array}$ & $3.2 \pm 0.3$ & $2.2 \pm 0.2 \dagger$ & $1.9 \pm 0.4 \dagger$ \\
$\begin{array}{l}\text { Fetal CaGlu }(n=7) \\
\text { Fetal CMRglu } \\
(n=5) \ddagger\end{array}$ & $1.3 \pm 0.2$ & $1.06 \pm 0.2 \dagger$ & $0.94 \pm 0.3 \dagger$ \\
$\begin{array}{l}\text { Fetal AV glucose } \\
(n=6) \S\end{array}$ & $0.18 \pm 0.06$ & $0.18 \pm 0.4$ & $0.17 \pm 0.09$ \\
$\begin{array}{l}\text { Maternal CaLact } \\
(n=7) \|\end{array}$ & $0.44 \pm 0.16$ & $1.27 \pm 0.47 \dagger$ & $1.61 \pm 0.50 \dagger$ \\
$\begin{array}{l}\text { Fetal CaLact }(n=7) \\
\text { Fetal AV lactate } \\
(n=6)\end{array}$ & $1.07 \pm 0.23$ & $1.29 \pm 0.31 \dagger$ & $1.23 \pm 0.34 \dagger$ \\
\hline
\end{tabular}

* CaGlu, arterial glucose concentration $(\mathrm{mM})$.

$\dagger p \leq 0.05$, compared with baseline.

$\ddagger$ CMRglu, cerebral glucose consumption $(\mu \mathrm{mol} / 100 \mathrm{~g} / \mathrm{min})$.

$\S \mathrm{AV}$ glucose (lactate), arteriovenous glucose (lactate) concentration difference $(\mathrm{mM})$.

\| CaLact, arterial lactate concentration (mM).

no significant decreases in blood flow to any of the three brain regions, or to the myocardium.

The effect of acute alcohol intoxication on cerebral oxygen metabolism is shown in Table 3. There were no significant changes in $\mathrm{CMRO}_{2}$, cerebral oxygen transport, or cerebral oxygen extraction, nor was there development of fetal hypoxemia.

Alcohol intoxication caused significant maternal hypoglycemia and lactic acidemia (Table 4). This effect was also noted in the fetus, but to a lesser extent. Despite the development of mild fetal hypoglycemia and lactic acidemia during alcohol intoxication (Table 4), there were no significant changes in fetal CMRglu or cerebral lactate flux.

\section{DISCUSSION}

The major finding of this study is that, in contrast to more mature fetal sheep, immature fetal sheep do not demonstrate significantly decreased $\mathrm{CBF}, \mathrm{CMRO}_{2}$, or CMRglu in response to acute maternal alcohol intoxication.

Cerebrovascular and metabolic responses to acute alcohol intoxication have been described by many investigators in a number of species. Several of these investigators have reported that alcohol constricts umbilical and cerebral blood vessels (912). Alcohol is generally regarded as a "depressant," and several studies have demonstrated that alcohol intoxication is associated with decreased $\mathrm{CMRO}_{2}$ and $\mathrm{CMRglu}$, presumably reflecting decreased functional activity $(5,10,13-15)$.

Few investigators have described the effects of alcohol on fetal sheep. Richardson et al. (5) studied near-term fetal sheep with the same dose of alcohol as used here and reported a $41 \%$ decrease in $\mathrm{CBF}$ and a $35 \%$ decrease in $\mathrm{CMRO}_{2}$ immediately after the infusion, both of which gradually returned toward baseline $1 \mathrm{~h}$ later. Mann et al. (16) also studied near-term fetal sheep but found an increase in CBF during alcohol intoxication. However, the latter studies were done acutely, in exteriorized fetal sheep under general anesthesia, a method that may result in fetal instability (17); furthermore, alcohol was infused as a dextrose solution.

Two factors could account for the absence of significant cerebral vascular and metabolic responsivity to alcohol in immature fetal sheep. One possibility is that alcohol's cerebrovascular and metabolic effects are mediated by metabolites such as acetaldehyde or other vasoactive substances whose metabolism, release, or cerebral effects may be undeveloped at midgestation. Another possibility is that $\mathrm{CMRO}_{2}$, which at midgestation is only $25 \%$ of measurements reported near term (6), is so low that any decrease induced by alcohol may be too small to be detected by the Fick method, which is rather insensitive to small changes in $\mathrm{CMRO}_{2}$. In fact, although our results do not demonstrate a significant decrease in $\mathrm{CBF}$ or $\mathrm{CMRO}_{2}$ during alcohol intoxication, mean $\mathrm{CBF}$ and $\mathrm{CMRO}_{2}$ at $1 \mathrm{~h}$ are slightly lower than baseline. It is possible that this decrease would become significant with the addition of more experiments. A marginal decrease in fetal CBF and $\mathrm{CMRO}_{2}$, although blunted compared with that in mature fetuses, could affect brain development if repeated over an extended period of time.

The immature fetal sheep in this study developed mild but persistent hypoglycemia. Hypoglycemia has been reported furing alcohol intoxication in mature fetal sheep (5) and adults (18). Although the mechanism is uncertain, alcohol is known to inhibit gluconeogenesis (19). Sheep depend upon gluconeogenesis to maintain glucose supply (20) and might be expected to have more severe alcohol-associated hypoglycemia. Cerebral responses to hypoglycemia have been studied in rats (21), newborn dogs (22) and preterm infants (23). There is generally an increase in $\mathrm{CBF}$, a decrease in CMRglu, or both, indicating a coupling of metabolic demand to glucose supply. In the present study, CMRglu did not decrease nor did CBF increase during alcoholinduced hypoglycemia, perhaps reflecting the mild degree of fetal hypoglycemia or different responses by the immature sheep brain to hypoglycemia.

Lactic acidemia has been noted during alcohol intoxication in adults (24), and in the present study both maternal and fetal arterial lactate concentrations were increased, although the increase was most significant for the mother. Lactate could be used as an energy substrate during hypoglycemia or, alternatively, less of the glucose consumed could be used for lactate production. However, we did not note lactate uptake by the immature fetal sheep brain during alcohol intoxication, nor was there any change in cerebral lactate production.

Several studies have demonstrated depressed myocardial function during acute alcohol intoxication in fetal sheep $(15,25,26)$. There was no change in myocardial blood flow in the immature fetal sheep in the presənt study nor were there any physiologically significant alterations in heart rate or blood pressure during alcohol intoxication.

Acute alcohol intoxication in immature fetal sheep is associated with fetal and maternal hypoglycemia and lactic acidemia but not with significant changes in $\mathrm{CBF}, \mathrm{CMRO}_{2}$, or CMRglu compared with mature fetal sheep. The reason for these apparent 
developmental differences in the fetal responses to acute maternal alcohol intoxication and the implications of these differences with respect to mechanisms of brain damage in fetal alcohol syndrome remain to be elucidated.

Acknowledgments. The authors thank Christine Roman for her excellent technical assistance, Lorretta Miller for her secretarial support, and Drs. Michael Heymann and Richard J. Traystman for their encouragement.

\section{REFERENCES}

1. Pietrantoni M, Knuppel RA 1991 Alcohol use in pregnancy. Clin Perinato 18:93-111

2. Clarren SK, Smith DW 1978 The fetal alcohol syndrome. N Engl J Med 2198:1063-1067

3. Clarren SK 1986 Neuropathology in fetal alcohol syndrome. In: West JR (ed) Alcohol and Brain Development. Oxford University Press, New York, pp $158-166$

4. Dow KE, Riopelle RJ 1987 Neurotoxicity of ethanol during prenatal development. Clin Neuropharmacol 10:330-341

5. Richardson BS, Patrick JE, Bousquet J, Homan J, Brien JF 1985 Cerebral metabolism in fetal lamb after maternal infusion of ethanol. Am J Physiol 249:R505-R509

6. Gleason CA, Hamm C, Jones Jr MD 1989 Cerebral blood flow, oxygenation, and carbohydrate metabolism in immature fetal sheep in utero. Am J Physiol 256:R1264-R1268

7. Gleason CA, Hamm C, Jones Jr MD 1990 Effect of acute hypoxemia on brain blood flow and oxygen metabolism in immature fetal sheep. Am J Physiol 258:H1064-H1069

8. Heymann MA, Payne BD, Hoffman JIE, Rudolph AM 1977 Blood flow measurements with radionuclide-labeled particles. Prog Cardiovasc Dis 20:55-79

9. Altura BM, Altura BT, Gebrewold A 1983 Alcohol-induced spasms of cerebral blood vessels: relation to cerebrovascular accidents and sudden death. Science $220: 331-333$

10. Hemmingsen R, Barry DI 1979 Adaptive changes in cerebral blood flow and oxygen consumption during ethanol intoxication in the rat. Acta Physiol Scand 106:249-255
11. Mukherjee AB, Hodgen GD 1982 Maternal ethanol exposure induces transient impairment of umbilical circulation and fetal hypoxia in monkeys. Science 218:708-702

12. Altura BM, Altura BT, Carella A, Chatterjee M, Halvey S, Tejani N 1983 Alcohol produces spasms of human umbilical blood vessels: relationship to fetal alcohol syndrome (FAS). Eur J Pharmacol 86:311-312

13. Sokoloff $L$ 1981 Relationships among local functional activity, energy metabolism, and blood flow in the central nervous system. Fed Proc 40:2311-2316

14. Richardson BS, Patrick JE, Abduljabbar H 1985 Cerebral oxidative metabolism in the fetal lamb: relationship to electrocortical state. Am J Obstet Gynecol 153:426-431

15. Patrick J, Richardson B, Hasen G, Clarke D, Wlodek M, Bousquet J, Brien $J$ 1985 Effects of maternal ethanol infusion on fetal cardiovascular and brain activity in lambs. Am J Obstet Gynecol 151:859-867

16. Mann LI, Bhakthavasthsalan A, Liu M, Marowski P 1975 Effect of alcohol on fetal cerebral function and metabolism. Am J Obstet Gynecol 122:845-851

17. Heymann MA, Rudolph AM 1967 Effect of exteriorization of the sheep fetus on its cardiovascular function. Circ Res 21:741-745

18. Williams HE 1984 Alcoholic hypoglycemia and ketoacidosis. Med Clin North Am 68:33-38

19. Field JB, Williams HE, Mortimore GE 1963 Studies on the mechanism of ethanol-induced hypoglycemia. J Clin Invest 42:497-506

20. Trenkle A 1981 Endocrine regulation of energy metabolism in ruminants. Fed Proc 40:2536-2541

21. Bryan RM, Hollinger BR, Keefer KA, Page RB 1987 Regional cerebral and neural lobe blood flow during insulin-induced hypoglycemia in unanesthetized rats. J Cereb Blood Flow Metab 7:96-102

22. Hernandez MJ, Vannucci RC, Salcedo A, Brennan RW 1980 Cerebral blood flow and metabolism during hypoglycemia in newborn dogs. J Neurochem 35:622-628

23. Pryds O, Christensen NJ, Friis-Hansen B 1990 Increased cerebral blood flow and plasma epinephrine in hypoglycemic, preterm neonates. Pediatrics 85:172-176

24. Kriesberg RA, Owen WC, Siegal AM 1971 Ethanol-induced hyperlacticacidemia: inhibition of lactate utilization. J Clin Invest 50:166-174

25. Kirkpatrick SE, Pitlick PT, Hirschklau MJ, Friedman WF 1976 Acute effects of maternal ethanol infusion on fetal cardiac performance. Am J Obstet Gynecol 125:1034-1037

26. Lafond JS, Fouron J-C, Bard H, Ducharme G 1985 Effects of maternal alcohol intoxication on fetal circulation and myocardial function: an experimental study in the ovine fetus. J Pediatr 107:947-950 